\title{
BMJ Global Health Integrated Disease Surveillance and Response (IDSR) strategy: current status, challenges and perspectives for the future in Africa
}

\author{
Ibrahima Socé Fall, ${ }^{1}$ Soatiana Rajatonirina, ${ }^{1}$ Ali Ahmed Yahaya, ${ }^{1}$ Yoti Zabulon, ${ }^{1}$ \\ Peter Nsubuga, ${ }^{2}$ Miriam Nanyunja, ${ }^{3}$ Joseph Wamala, ${ }^{4}$ Charles Njuguna, ${ }^{5}$ \\ Charles Okot Lukoya, ${ }^{1}$ Wondimagegnehu Alemu, ${ }^{6}$ Francis Chisaka Kasolo, ${ }^{7}$ \\ Ambrose Otau Talisuna ${ }^{\circledR}$
}

To cite: Fall IS, Rajatonirina S, Yahaya AA, et al. Integrated Disease Surveillance and Response (IDSR) strategy: current status, challenges and perspectives for the future in Africa. BMJ Global Health 2019;4:e001427. doi:10.1136/ bmjgh-2019-001427

Handling editor Seye Abimbola

Received 19 January 2019 Revised 13 May 2019 Accepted 18 May 2019
Check for updates

\section{Author(s) (or their} employer(s)) 2019. Re-use permitted under CC BY-NC. No commercial re-use. See rights and permissions. Published by BMJ.

For numbered affiliations see end of article.

Correspondence to Dr Ambrose Otau Talisuna; talisunaa@who.int

\section{ABSTRACT}

In 1998, the WHO African region adopted a strategy called Integrated Disease Surveillance and Response (IDSR). Here, we present the current status of IDSR implementation; and provide some future perspectives for enhancing the IDSR strategy in Africa.

In 2017, we used two data sources to compile information on the status of IDSR implementation: a pretested rapid assessment questionnaire sent out biannually to all countries and quarterly compilation of data for two IDSR key performance indicators (KPI). The first KPI measures country IDSR performance and the second KPI tracks the number of countries that the WHO secretariat supports to scale up IDSR. The KPI data for 2017 were compared with a retrospective baseline for 2014.

By December 2017, 44 of 47 African countries (94\%) were implementing IDSR. Of the 44 countries implementing IDSR, $40(85 \%)$ had initiated IDSR training at subnational level; 32 (68\%) had commenced community-based surveillance; 35 (74\%) had event-based surveillance; 33 (70\%) had electronic IDSR; and 32 (68\%) had a weekly/ monthly bulletin for sharing IDSR data. Thirty-two countries $(68 \%)$ had achieved the timeliness and completeness threshold of at least $80 \%$ of the reporting units. However, only 12 countries (26\%) had the desired target of at least $90 \%$ IDSR implementation coverage at the peripheral level. After 20 years of implementing IDSR, there are major achievements in the indicator-based surveillance systems. However, major gaps were identified in event-based surveillance. All African countries should enhance IDSR everywhere

\section{INTRODUCTION}

Annually, over 100 infectious disease outbreaks and other public health emergencies occur in the WHO African region. ${ }^{1}$ No country in the region is spared from the risks of health emergencies. ${ }^{1}{ }^{2}$ This situation is concerning because, in today's globalised world, conducive environments
Summary box

- By 1998, major weaknesses in national public health surveillance and response systems in many African countries had been widely recognised. In response, the WHO African region proposed the Integrated Disease Surveillance and Response (IDSR) strategy as an Africa-wide strategy to strengthen public health surveillance and response. The goal of IDSR is to efficiently integrate multiple 'categorical' surveillance and response systems and linking surveillance, laboratory and other data with public health action.

- In 2017, we used two data sources to compile information on the status of IDSR implementation: (1) a pretested rapid assessment questionnaire (quantitative and qualitative) was sent out biannually to all countries and (2) quarterly analysis of two IDSR key performance indicators (KPI). The KPIs for 2017 were compared with a retrospective baseline for 2014 .

- As of December 2017, 44 of 47 countries (94\%) were implementing IDSR. Of the 44 countries implementing IDSR, 40 (85\%) had initiated IDSR training at subnational level; 32 countries $(68 \%)$ had commenced community-based surveillance; 35 (74\%) had event-based surveillance, although to varying degrees; 33 (70\%) had electronic IDSR; and 32 $(68 \%)$ had a weekly/monthly bulletin for sharing IDSR data. Thirty-two countries (68\%) had achieved the timeliness and completeness threshold of at least $80 \%$ of the reporting units. However, only 12 countries $(26 \%)$ had the desired target of at least $90 \%$ IDSR implementation coverage at the peripheral level.

- All African countries should enhance IDSR everywhere, because it has contributed to early detection and timely effective response to public health emergencies.

for pandemics exist, including: dense human populations, an unprecedented volume of transnational movement, rapid travel, civil 
unrest and conflict, and global inequalities in economics and health. ${ }^{3-5}$ Recent major outbreaks in the region have demonstrated the need for a robust global infectious disease control regime. ${ }^{3-5}$ The fragile national systems that are charged with detecting and responding to public health emergencies are burdened by external pressures due to regional and global events such as civil conflicts resulting in internally displaced populations, environmental and climate change resulting in extreme drought and acute water shortages, often followed by unusually heavy rains. ${ }^{6}$ The latter often leads to a high risk of vectorborne and communicable disease outbreaks. ${ }^{89}$

Outbreaks and other public health emergencies are well known to cause major socioeconomic consequences. For example, the Ebola virus disease (EVD) outbreak (2013-2016) in West Africa resulted in over 11000 deaths and an economic loss estimated at US\$3 billion. ${ }^{10-16}$ Infectious diseases are expected to continue to emerge and re-emerge unpredictably in silent places because of the lack of adequate and resilient public health surveillance systems and infrastructure, resulting in limited preparedness for controlling the devastating health events. ${ }^{1718}$

\section{EVOLUTION OF THE INTEGRATED DISEASE SURVEILLANCE AND RESPONSE STRATEGY}

In 1998, following the re-emergence of large outbreaks due to meningitis, cholera, yellow fever and measles in West Africa, ministers for health from the Member States of the WHO African region called on the WHO secretariat to support countries to improve their disease surveillance and response capabilities so that they could detect and timely respond to communicable disease threats. ${ }^{19} 20$ The strategy was first named the Integrated Disease Surveillance strategy. However, in 2000, the strategy was renamed Integrated Disease Surveillance and Response (IDSR) to emphasise the essential link between surveillance and response. IDSR is a comprehensive, evidence-based strategy for strengthening national public health surveillance and response systems at the community, health facility, 'district' and national level. The strategy makes explicit the skills, activities and resources needed at each level of the health system to operate all functions of surveillance. ${ }^{19-21}$

In order to scale up IDSR at country level, the WHO secretariat in collaboration with technical partners developed several guidelines and tools to provide countries with the technical elements necessary to support them in their operationalising of IDSR across all levels (figure 1). These include: a set of generic IDSR technical guidelines (first edition, 2002; second edition, 2010; third edition, in press, 2019).$^{22}$ In addition, the following were developed: IDSR training modules, an eSurveillance concept note, advocacy materials, community-based surveillance (CBS) guidelines and CBS training manual, a guide for the introduction of IDSR in training institutions; a guide for national public health laboratory networking; and a guide for initial assessment, planning and indicators for monitoring and evaluation of IDSR implementation.

Several steps are required to initiate IDSR implementation in the countries, including: (1) sensitisation of national officials and stakeholders; (2) assessment of existing surveillance systems; (3) development of a national plan of action; (4) adaptation of the generic IDSR guidelines and training materials; (5) conducting a training of trainers (ToT) on IDSR followed by cascade IDSR training of health workers at all levels of the health system and finally (6) monitoring and evaluation of the IDSR implementation. WHO (regional and country offices) and other partners provide technical and financial support to countries along these implementation steps.

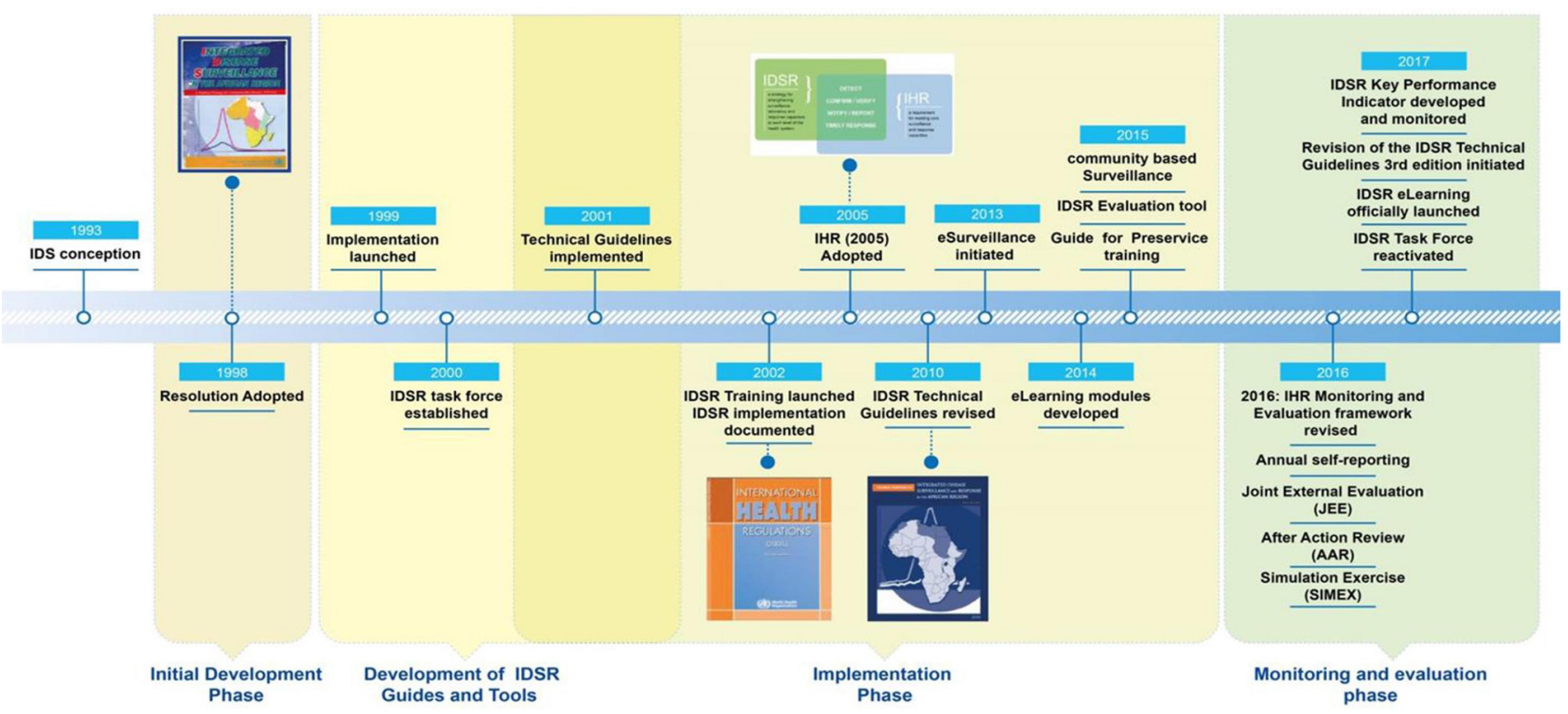

Figure 1 Integrated Disease Surveillance and Response (IDSR) steps and milestones. IDS, integrated disease surveillance; IHR, International Health Regulations. 


\section{IDSR AND INTERNATIONAL HEALTH REGULATIONS (2005)}

The International Health Regulations (IHR, 2005) are a key legal instrument for addressing global health security. The IHR aim at helping countries to prevent, detect and respond to acute public health risks that have the potential to cross borders and threaten people worldwide. ${ }^{23}$ Since their revision in 2005, the IHR have been tested by four public health emergencies of international concern (PHEIC)-the 2009 H1N1 influenza pandemic, ${ }^{24}$ the wild poliovirus outbreak in $2014,{ }^{25}$ the 2014 EVD epidemic in West Africa ${ }^{26}$ and the Zika virus epidemics in $2016 .{ }^{27}$ These PHEICs have revealed significant challenges in IHR compliance and effectiveness. ${ }^{28} 29$ The goal of IDSR is to strengthen the overall national system for public health surveillance and response. Consequently, implementing IDSR is likely to fast-track the achievement of the required IHR (2005) capacities.

\section{IDSR AND THE WHO AFRICAN REGION'S TRANSFORMATION AGENDA}

Following the unprecedented 2013-2016 West Africa EVD outbreak, in 2016, Member States in the WHO African region adopted the regional strategy for health security and emergencies (2016-2020) ${ }^{30}$ Earlier in 2015, the new Regional Director unveiled the transformation agenda which stipulate reforms in the operations of the WHO secretariat so that it is able to more effectively support countries. ${ }^{31}$ As a result of these developments, in 2016, several key performance indicators (KPI) were formulated to measure progress. Two KPIs were selected to specifically track progress in IDSR implementation. One of the KPIs measures country IDSR performance and is referred to as the health driver development (HDD) indicator and the other measures WHO secretariat performance and is referred to as the WHO attributable contribution (WAC) indicator. The regional strategy for health security stipulates that by 2020 , over $90 \%$ of the Member States should be implementing IDSR (indicator and event-based surveillance (EBS)) with at least $90 \%$ country coverage of subnational and peripheral level health facilities and communities. ${ }^{30}$

Here, we present the status of the IDSR strategy implementation in the WHO African region as of December 2017, and propose ways for its future enhancement and scale-up.

\section{ASSESSING THE WHO SECRETARIAT AND COUNTRY-LEVEL IDSR IMPLEMENTATION PERFORMANCE}

Between January and December 2017, we analysed surveillance monitoring data from all 47 countries in the WHO African region using two data sources: (1) biannual pretested IDSR rapid assessment questionnaires sent to all countries and (2) quarterly IDSR KPI monitoring. The biannual questionnaires included quantitative and qualitative indicators for IDSR implementation, such as: adaptation of the IDSR technical guidelines; IDSR ToT; IDSR cascade training for health workers up to the peripheral-level health facilities; implementation of EBS and CBS; implementation of electronic IDSR (eIDSR); and timeliness and completeness of IDSR reporting. All focal persons for IDSR at each WHO country office and the Ministry of Health $(\mathrm{MoH})$ were trained on the new KPIs and their obligations for timely reporting before the roll-out of the quarterly IDSR implementation monitoring. IDSR KPI data for 2014 were retrospectively collected to serve as the baseline. The KPIs are colour coded using 'a traffic lights' colour code system as follows: For the IDSR KPI which measures country performance (HDD): green implies that implementation of IDSR is ongoing with at least $90 \%$ coverage of subnational levels; yellow implies that implementation of IDSR is ongoing, but coverage is between $50 \%$ and $89 \%$ of subnational levels; and red reflects that implementation of IDSR is ongoing, but coverage is less than $50 \%$ of subnational levels. Similarly, for the IDSR KPI which measures WHO performance (WAC), green implies that a Member State has adapted the IDSR guidelines and tools and has trained over $90 \%$ health workers at all levels; yellow-a Member State has adapted the IDSR guidelines and tools and has trained at least between $50 \%$ and $89 \%$ of the health workers at all levels; and red-a Member State has adapted the IDSR guidelines and tools and has trained less than $50 \%$ of the health workers at all levels. The IDSR focal person from the $\mathrm{MoH}$ in collaboration with the focal person at WHO country office was responsible for completing the questionnaire and transmitting the information to the WHO regional office. All data were collected, compiled and stored in Microsoft Excel and went through a validation process before analysis. Microsoft Excel was used to perform descriptive analysis and maps were generated using Adobe Illustrator CC 2014.

Timeliness and completeness of IDSR reporting was recorded as timely when the data were submitted on time as stipulated by national guidelines to the next level of the health system. ${ }^{25}$ Timeliness of IDSR weekly reporting was defined as: the total number of reports received on time for the week divided by the number of reports expected in the week and expressed as a percentage. Completeness of IDSR weekly reporting was measured using the proportion of reporting units that submitted the surveillance report irrespective of the time the report was submitted. ${ }^{25}$ Completeness of weekly IDSR reporting was defined as: the total number of reports received within the week (irrespective of time of receipt) divided by the number of reports expected in the week and expressed as a percentage.

The broad scope of the IHR (2005) introduced the notion of 'event-based' surveillance to address rumours of 'unexplained illness or clusters' as an event category for reporting from lower levels to the national level. EBS is the organised and rapid capture of information about events that are of potential risk to public health. Information is initially captured as an alert representing a potential acute risk to human health, such as an outbreak. All alerts may not necessarily become real events, as such 
they all need to be triaged and verified before a response is initiated. Alerts which may signify potential risks could include: unexplained clustering of cases of a disease or syndromes, unusual disease patterns or unexpected deaths in the community; potential exposure for humans to toxins, diseases and deaths in animals, contaminated food products or water, and environmental hazards including chemical and radionuclear events.

EBS also involves media monitoring, which entails the regular scanning of newspapers, internet sites and media alert systems such as ProMed, blogs, social media, radios and television. EBS systems are very sensitive. Information received through EBS should be synchronised with information from indicator-based surveillance (IBS) and rapidly assessed for the risk the event poses to public health and should be responded to appropriately.

Unlike IBS, EBS is not based on the routine monitoring of indicators and automated thresholds for action but rather on the screening of all available information to detect any event happening in the community (unusual disease or deaths in humans or animals, unusual or clustering of cases, events/conditions in the community, including environmental conditions). We assessed the status of EBS implementation in the countries.

Finally, we assessed the status of CBS. CBS is the systematic detection and reporting of events of public health significance within a community by community members. CBS incorporates both IBS and EBS methods. In CBS, there are identified focal persons who report cases or events to the nearby local health facilities. CBS strategies focus on two approaches to collect community information. The first one relies on identifying and reporting events based on agreed lay case definitions. For example, trusted community members are trained to identify diseases such as: measles, cholera, polio and guinea worm, using a standardised reporting system to the next level. The second strategy relies on reporting of unusual events (alerts) which can detect the occurrence of an outbreak or any other public health threat in the community. Alerts may capture a wide variety of unusual events within the community. Information from these alerts may be incomplete and unconfirmed and as such needs to be triaged and verified. Information using this strategy can also come from people who have already been oriented on the agreed indicators (lay case definitions), for example, the CBS volunteers, or may be any other representatives from the community, who have been oriented to detect events like unusual animal deaths and report to the next level. Often, CBS focal persons would link the case identified through any of the above strategies, to the nearby health facility and can help identify contacts.

\section{CURRENT STATUS OF IDSR IMPLEMENTATION}

By December 2017, based on the rapid assessment questionnaire, 44 of 47 countries (94\%) were implementing the IDSR strategy. Only Algeria, Cabo Verde and Mauritius had not adapted the second edition of the IDSR technical guidelines (table 1).

Forty countries $(85 \%)$ had initiated IDSR training at the district or equivalent level. Thirty-five countries $(74 \%)$ had started EBS; 32 countries $(68 \%)$ had commenced CBS; 33 countries (70\%) were using eIDSR systems; and 32 countries $(68 \%)$ had a feedback mechanism for sharing national IDSR data through a weekly or monthly bulletin. Further, 34 countries $(72 \%)$ were providing information on the timeliness and completeness of IDSR reporting, and $68 \%$ of them had achieved the IDSR timeliness and completeness threshold of at least $80 \%$ of the reporting units. However, only 12 countries $(26 \%)$ had the desired target of at least $90 \%$ IDSR implementation coverage at peripheral health facilities as of 2017 (table 2).

When we analysed the IDSR KPIs comparing data for 2014 to that of 2017,12 countries (26\%) had adapted the IDSR guidelines and tools and conducted training with a coverage of $90 \%$ of health workers at all levels (national and subnational) compared with only 6 countries (13\%) in 2014; 22 countries (47\%) that had adapted the IDSR guidelines and tools had conducted training with coverage between $50 \%$ and $89 \%$ of health workers at all levels; and 11 countries $(23 \%)$ had a training coverage of less than $50 \%$ of health workers at all levels (figures 2 and 3).

The proportion of countries implementing EBS was $74 \%$ (35 of 47) (figure 4A), while that for countries that had commenced CBS implementation was $68 \%$ (32 of 47) (figure 4B), and 70\% (33 of 47) reported having eIDSR systems (figure 4C). About $42 \%$ of the countries did not have data on the implementation coverage of EBS, CBS or eIDSR. Only 10 countries (21\%) were implementing EBS with $100 \%$ 'district' coverage and only 7 countries (15\%) were implementing CBS with $100 \%$ 'district' coverage. It is concerning that only four countries had both EBS and CBS with 100\% 'district' coverage.

With respect to sharing of information, 32 countries $(68 \%)$ had a feedback mechanism for sharing IDSR data through weekly or monthly bulletins and 34 countries provided information on timeliness and completeness of IDSR reporting, with 23 of them meeting the timeliness and completeness threshold of $80 \%$ or above. Among the 23 countries with good performance on the timeliness of data reporting, 18 had an eIDSR system.

\section{SOME LIMITATIONS}

A key limitation of our analysis is not assessing the quality of the IDSR being implemented. The latter requires periodic data quality audits for the different functions of IDSR. In the revised IDSR strategy, we have incorporated 15 indicators that should be tracked to assess the scale-up of IDSR implementation. Further, the coverage of the HDD KPI is also based on peripheral health facilities and not population coverage and may thus exclude underserved populations. Moving forward, periodic analysis of whether any events are missed and the timeliness of the response to all events should be able to alleviate this limitation. Despite 
Table 1 Country IDSR implementation status from January to December 2017

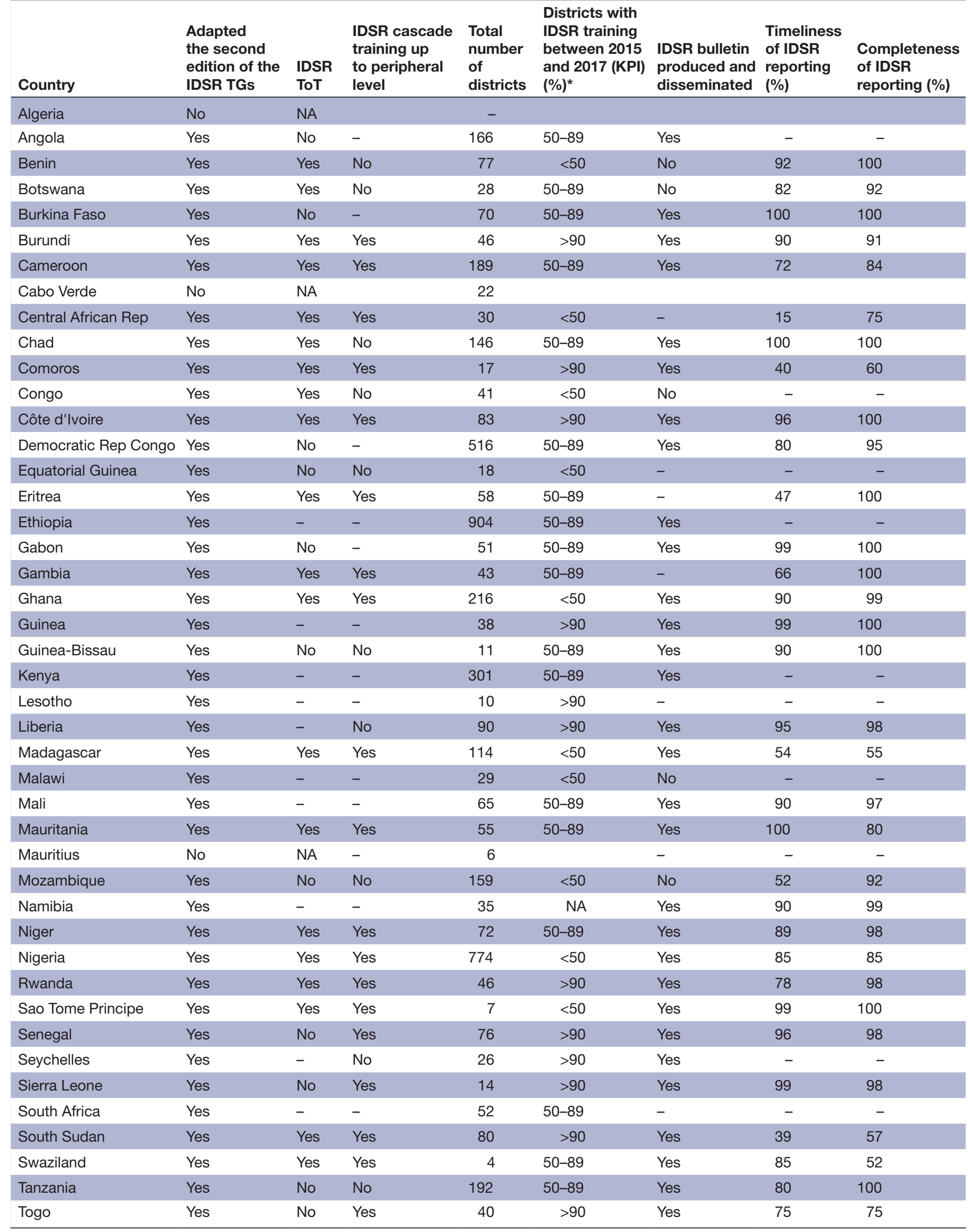


Table 1 Continued

\begin{tabular}{|c|c|c|c|c|c|c|c|c|}
\hline Country & $\begin{array}{l}\text { Adapted } \\
\text { the second } \\
\text { edition of the } \\
\text { IDSR TGs }\end{array}$ & $\begin{array}{l}\text { IDSR } \\
\text { ToT }\end{array}$ & $\begin{array}{l}\text { IDSR cascade } \\
\text { training up } \\
\text { to peripheral } \\
\text { level }\end{array}$ & $\begin{array}{l}\text { Total } \\
\text { number } \\
\text { of } \\
\text { districts }\end{array}$ & $\begin{array}{l}\text { Districts with } \\
\text { IDSR training } \\
\text { between } 2015 \\
\text { and } 2017 \text { (KPI) } \\
(\%)^{\star}\end{array}$ & $\begin{array}{l}\text { IDSR bulletin } \\
\text { produced and } \\
\text { disseminated }\end{array}$ & $\begin{array}{l}\text { Timeliness } \\
\text { of IDSR } \\
\text { reporting } \\
(\%)\end{array}$ & $\begin{array}{l}\text { Completeness } \\
\text { of IDSR } \\
\text { reporting (\%) }\end{array}$ \\
\hline Uganda & Yes & Yes & Yes & 116 & $>90$ & Yes & 69 & 70 \\
\hline Zambia & Yes & - & - & 105 & $50-89$ & Yes & - & - \\
\hline Zimbabwe & Yes & Yes & - & 63 & $50-89$ & - & 90 & 90 \\
\hline
\end{tabular}

The symbol '-' denotes information not provided.

*Training conducted in end of 2016.

IDSR, Integrated Disease Surveillance and Response; KPI, key performance indicator; NA, not applicable; TG, technical guidelines; ToT, training of trainers.

these limitations our analysis presents a robust status of IDSR implementation in the WHO African region.

\section{CHALLENGES}

The implementation of the IDSR strategy should be conducted at the health facility and community level with strong technical support from the district health management teams and the national level. It is apparent that the initial momentum observed in IDSR implementation during the period 2000-2010 was not sustained..$^{32-35}$ This could be linked to several factors, including: the lack of sustainable domestic resources due to a low buy-in from governments to ensure a robust functioning of IDSR; inadequate training and high turnover of peripheral staff;

\begin{tabular}{|c|c|c|}
\hline Indicator & $\begin{array}{l}\text { Status } \\
(\mathrm{n}=47)\end{array}$ & $\begin{array}{l}\text { Target } \\
\text { (achieved) }\end{array}$ \\
\hline Countries implementing IDSR & 44 & $100 \%(94 \%)$ \\
\hline $\begin{array}{l}\text { Countries that have initiated IDSR } \\
\text { training at district level }\end{array}$ & 40 & $100 \%(85 \%)$ \\
\hline $\begin{array}{l}\text { Countries that have commenced } \\
\text { event-based surveillance (EBS) in } \\
\text { the context of IDSR }\end{array}$ & 35 & $100 \%(74 \%)$ \\
\hline $\begin{array}{l}\text { Countries providing information on } \\
\text { the timeliness and completeness of } \\
\text { IDSR reporting }\end{array}$ & 34 & $100 \%(72 \%)$ \\
\hline $\begin{array}{l}\text { Countries using electronic IDSR } \\
\text { systems }\end{array}$ & 33 & $100 \%(70 \%)$ \\
\hline $\begin{array}{l}\text { Countries that have started } \\
\text { community-based surveillance } \\
\text { (CBS) in the context of IDSR }\end{array}$ & 32 & $100 \%(68 \%)$ \\
\hline $\begin{array}{l}\text { Countries that have achieved } \\
\text { IDSR timeliness and completeness } \\
\text { reporting } \geq 80 \%\end{array}$ & 23 & $100 \%(49 \%)$ \\
\hline $\begin{array}{l}\text { Countries that have the desired } \\
\text { target of at least } 90 \% \text { IDSR } \\
\text { implementation coverage at } \\
\text { peripheral health facilities }\end{array}$ & 12 & $100 \%(26 \%)$ \\
\hline
\end{tabular}

IDSR, Integrated Disease Surveillance and Response. inadequate sharing of surveillance data and information; inadequate supervision and mentorship; weak laboratory capacities; and reduced availability of communication and transport systems particularly at the peripheral level.

\section{PERSPECTIVES FOR THE FUTURE}

A key outcome of the 2015 Cape Town meeting on 'Building Health Security beyond Ebola' was a call for a global focus for addressing health security with priority countries identified in Africa. ${ }^{36}$ WHO was mandated to propose a collective, coherent and synergistic approach among international and national stakeholders to best support joint assessments in countries and to develop, implement and test national plans, as well as assume an active coordinating, convening and monitoring role. Partners were mandated to commit to working closely and actively with WHO and between each other in sharing relevant information and in making their technical and funding contributions as complementary, synergistic and coordinated as possible with existing strategies and frameworks. Countries were mandated to commit to providing national leadership and sustained support and resources. ${ }^{36}$ Moving forward, there is a need for high-level advocacy and policy dialogue with countries to prioritise IDSR as part of the solution to public health challenges facing the world and the countries to prevent, detect and respond to outbreaks and other public health emergencies.

We propose the following actions to strengthen the implementation of the revised IDSR strategy.

\section{Conducting high-level advocacy}

Success of IDSR implementation requires high-level advocacy at national and subnational levels to facilitate the mobilisation of domestic resources. The scale and scope of advocacy at country level should be adapted to the decentralisation or devolution context. At the regional and global level, there is a need to advocate for increased funding for IDSR from bilateral and multilateral partners.

\section{Ensuring good system design and country ownership}

For any system such as IDSR to be anchored on a sound foundation, programme design, accountability, 
2014

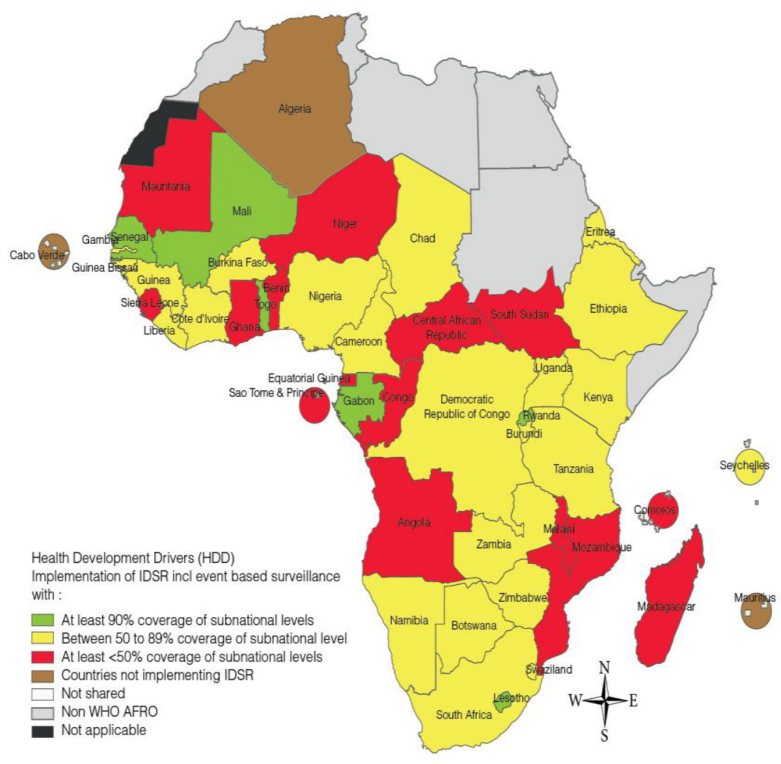

2017

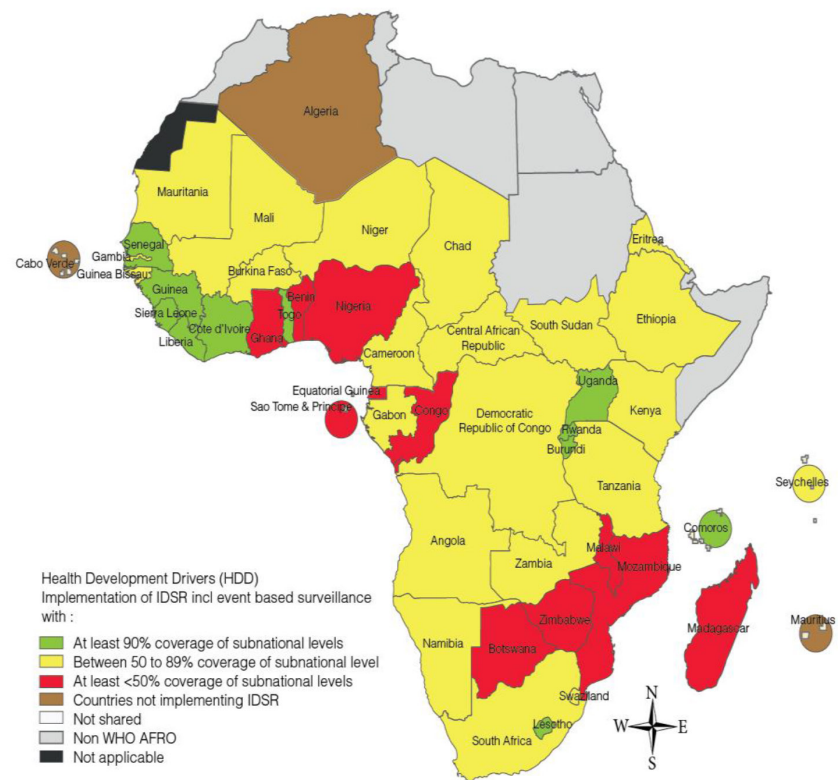

Figure 2 Status of IDSR key performance indicator (KPI) for country performance (health driver development, HDD) in 2014 and 2017. IDSR, Integrated Disease Surveillance and Response.

leadership, stakeholder engagement and an enabling environment are important considerations. ${ }^{37}$ Further, flexibility of programme design is critical. The IDSR strategy from its inception has been flexible. However, national ownership needs to be strengthened. During the IDSR adaptation process, countries should ensure that IDSR suits the prevailing local context. Considerations should include identification of epidemic-prone diseases and conditions for immediate and weekly reporting and other diseases and conditions selected for surveillance for monthly or quarterly reporting. However, such an adaptation will require robust EBS and timely verification systems. Programme objectives should guide diseases and conditions for immediately, weekly, monthly or quarterly

2014

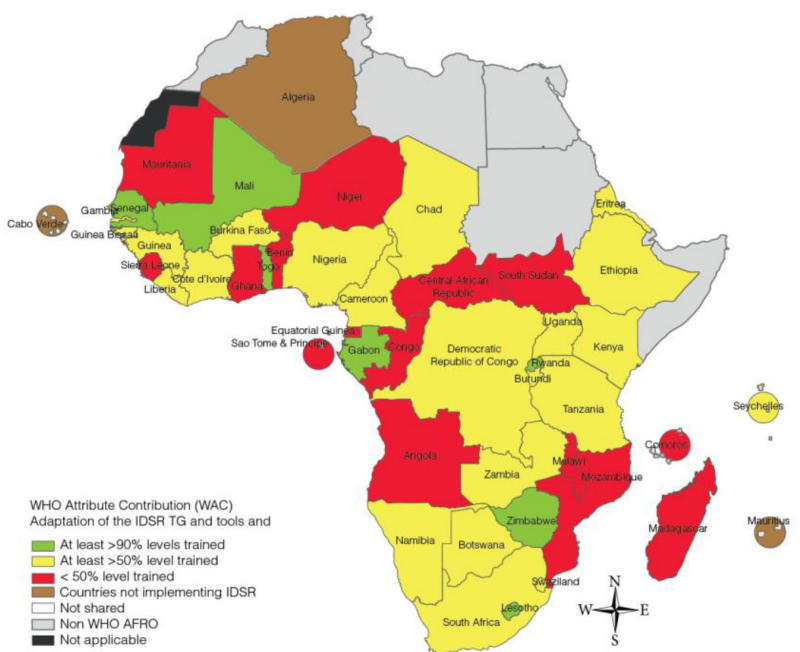

reporting. Importantly, a good enabling environment is indispensable. Therefore, the political, economic, epidemiological and social setting should be given key considerations. All countries should strive to devote additional resources (skilled human resources, infrastructure and funding) to support scaling up of IDSR implementation to all health facilities and communities.

\section{Optimising good leadership and robust accountability frameworks}

Enhancing IDSR requires good leadership and accountability at all levels of the health system. Moreover, supervision, monitoring and evaluation should be highlighted from the onset through the identification of indicators

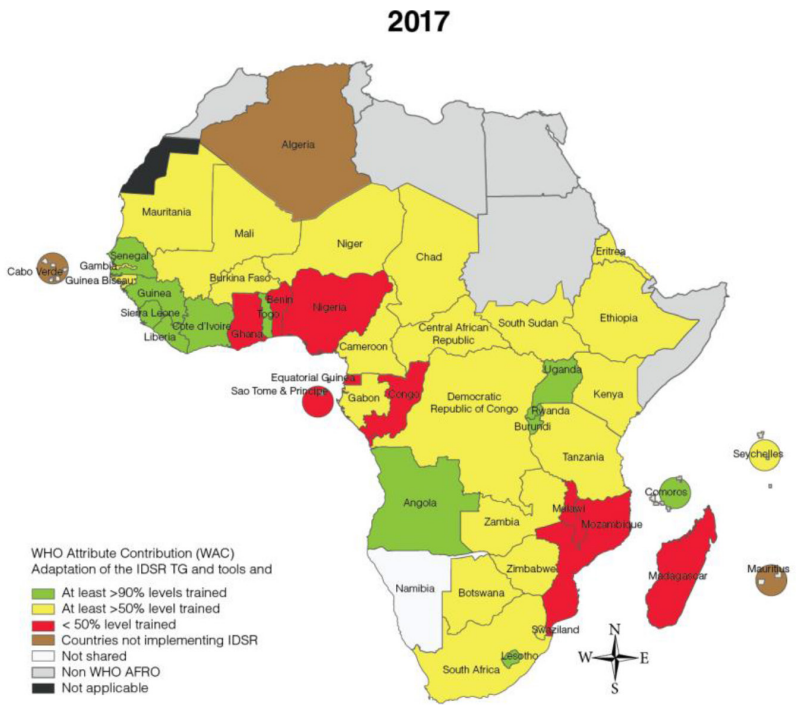

Figure 3 Status of IDSR key performance indicators (KPI) for WHO attributable contribution (WAC) performance in 2014 and 2017. IDSR, Integrated Disease Surveillance and Response; TG, technical guidelines. 


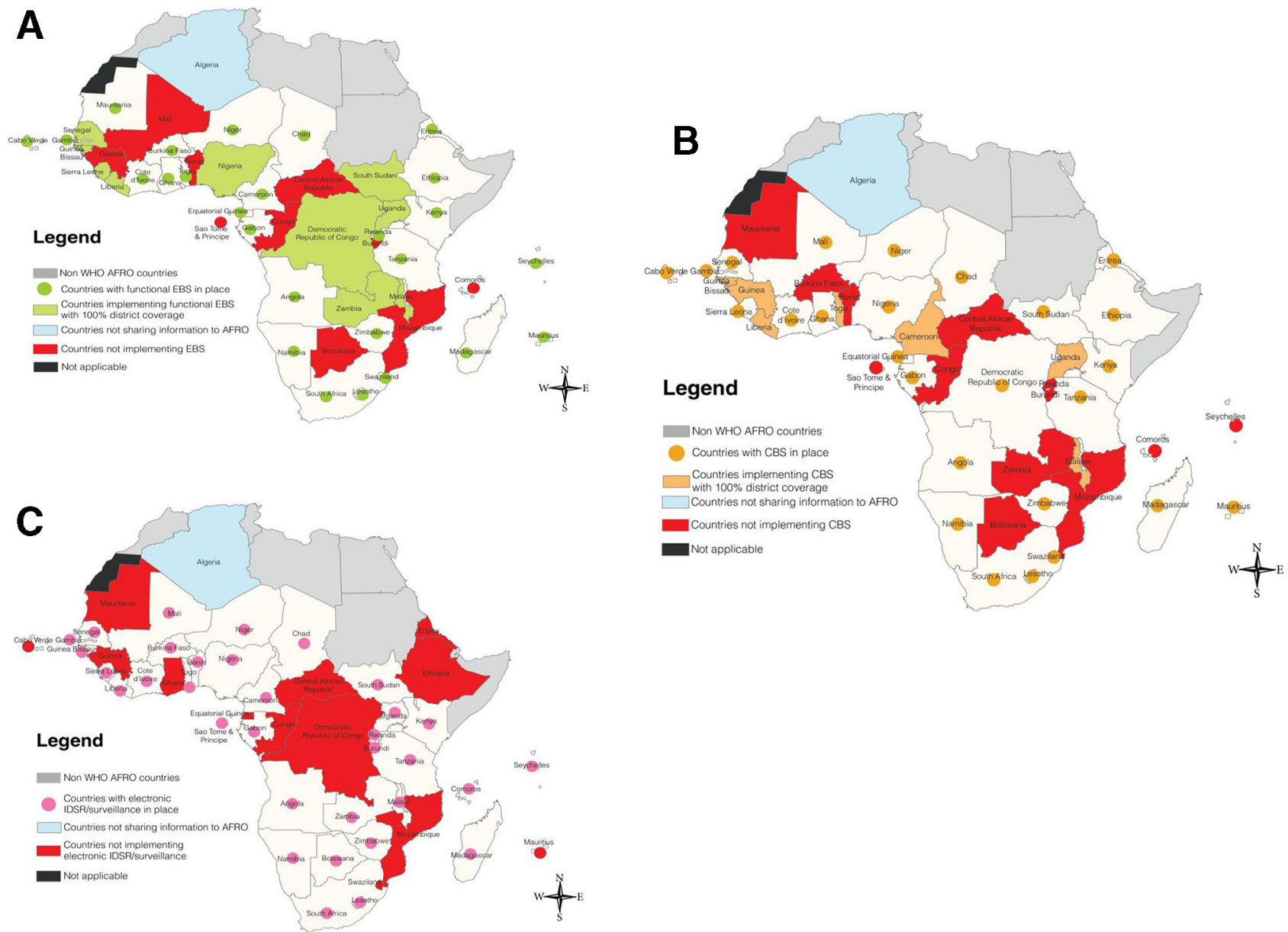

Figure 4 (A) Countries implementing event-based surveillance, as of December 2017. (B) Countries implementing communitybased surveillance, as of December 2017. (C) Countries implementing electronic Integrated Disease Surveillance and Response (IDSR), as of December 2017.

for measuring progress. Supervision and follow-up is critical for performance improvement and fostering accountability for the implementation of IDSR. Based on lessons learnt from countries, the third edition of the IDSR guidelines emphasises improved supervision, including the use of electronic supervision. Critical considerations in engaging relevant stakeholders should include the channels of communication, use of incentives, stakeholder analysis and local capacity building.

\section{Ensuring consistent availability of skilled health workers}

A critical factor to successful IDSR implementation is the consistent availability of a reliable, competent and motivated workforce across all levels of the health system but more so at peripheral health facilities and in the community. The African region is still facing challenges of insufficient numbers of trained personnel and high turnover of staff which threatens national, regional and international security. For example, in 2017, only 13341 (11\%) out of 121587 health personnel working on surveillance were trained based on data received from the assessment questionnaire. Given the high number of public health events occurring in the region, workshop-based training approaches might not reach all the health workers.
Consequently, an eLearning platform was launched in 2017 as an innovative training approach. The latter offers an excellent opportunity to efficiently increase the availability of trained human resources for scaling up IDSR implementation. It is still in its early stages, and we have not evaluated its benefits.

\section{Institutionalising IDSR training and review of curricula of training institutions}

While eLearning could be one of the solutions, the training gap noted above is a red flag about the urgent need for systematic in-service and preservice training of all health workers on IDSR and health security. To address the huge gap in the short term, we urge countries to institutionalise the training of IDSR and health security into public health training institutions. We also urge all governments to establish criteria for assigning surveillance officers at subnational administrative levels. Institutionalising IDSR and IHR training in all preservice training institutions will in the future mitigate the human resource challenges. To address, this WHO is working with training institutions to review their training curricula so that they explicitly address IDSR and IHR. This will be done in schools of public health, medical 
schools, schools of nursing, health training schools, veterinary schools, mid-level training colleges and field epidemiology training programmes, among others. The inclusion of the IDSR training in the preservice curriculum will ensure that training will be tailored to job requirements. Most importantly, it will provide a reliable and continuous supply of a well-trained workforce ready to be deployed to implement IDSR.

\section{Scaling up EBS}

The IHR (2005) introduced the notion of 'event-based' surveillance to address rumours of 'unexplained illness or clusters' as an event category for reporting. EBS was added to second edition of the IDSR guidelines. However, its implementation has been inadequate. Implementation of EBS requires the involvement of multiple stakeholders, the community and use of media scanning using information technology products and software. The IDSR third edition technical guidelines and training modules offer guidance to countries on how to scale up EBS. All countries are urged to scale up nationwide the implementation of EBS.

\section{Scaling up CBS}

CBS is an active process of community participation in detecting, reporting, responding to and monitoring health events in the community. The scope of CBS is limited to the systematic ongoing collection of data on events and diseases using simplified case definitions and forms and reporting to health facilities any unusual events for verification, investigation, collation, analysis and response as needed. CBS requires the participatory engagement of local communities. To address gaps in CBS, the third edition of the IDSR guideline has beefed up guidance on how to set up and scale up CBS and all countries are urged to use the opportunity offered by the IDSR revision to scale up CBS.

\section{Scaling up electronic IDSR}

Electronic surveillance systems are increasingly being adopted for prompt disease detection and monitoring, improved effectiveness of data collection and improved data analysis and information dissemination. We have learnt from Rwanda that several elements are required for the successful implementation of a national electronic surveillance system, including political commitment, secure toll-free numbers, piloting before national roll-out; periodic data quality assessments; appropriate training; and regular feedback and sharing of information among relevant stakeholders. Rwanda has been able to achieve national coverage and high levels of timeliness and completeness of reporting. ${ }^{38}$ Madagascar has also demonstrated that use of mobile phone short message service text messaging improves IDSR data completeness but improving timeliness and data quality was more challenging. ${ }^{39}$ The study in Madagascar highlighted the need for healthcare staff training on IDSR. ${ }^{39}$ Our analysis shows that among 20 countries with good timeliness of
IDSR reporting, 15 have electronic surveillance systems. In view of the latter, the third edition of the IDSR technical guidelines and training modules have dedicated a specific section and module on the implementation of eIDSR or eSurveillance. Countries are therefore urged to scale up eIDSR implementation nationwide.

\section{Providing feedback and information sharing}

Periodic regular consistent feedback and sharing of data on IDSR priority diseases, conditions and events in a timely manner across all levels of the health system and with WHO requires improvement in several countries. Weekly data reporting for IDSR priority diseases, conditions and events from countries to WHO is inadequate. Data and information sharing is critical for early detection, timely action, and leads to better evidence-led decision-making. Under the IHR, all countries are required to promptly share data (epidemiological and laboratory), as well as epidemiological bulletins.

\section{Integrating with broader health information systems}

IDSR should be aligned with broader health information systems of the countries. This will require explicit efforts so that the units responsible for IDSR are integrated within the units responsible for health management information systems.

\section{Implementing IDSR in complex situations}

Humanitarian crises and public health emergencies have affected IDSR performance in several countries due to the disruption of health and other social services. Based on the experiences from South Sudan and Nigeria, the second edition of the IDSR technical guidelines is currently being revised to include several key components and lessons learnt from implementing IDSR in humanitarian crises.

\section{CONCLUSIONS}

This paper demonstrates that enhancement and scale-up of IDSR in countries is urgently needed to increase early detection and reporting of suspected cases of priority diseases, conditions and events. Early detection facilitates prompt effective response to outbreaks and other public health emergencies. In countries where IDSR is fully implemented with nationwide coverage, it has reduced the magnitude of outbreaks with respect to response time, morbidity and mortality and duration of the outbreaks. ${ }^{40}$ Effective implementation of IDSR nationwide requires high-level advocacy as part of the broader advocacy for improved regional and national health security through building and sustaining the IHR capacity and resilient health systems.

Importantly, countries need to develop and test strategies for having and retaining an adequate public health workforce. And countries should adopt innovative approaches for capacity development, including: a paradigm shift from theoretical workshop-based trainings to approaches that reinforce knowledge, skills and 
competencies through regular simulation exercises; functional drills, backed by the use of innovations in technologies to strengthen eIDSR, mHealth approaches, eLearning and eTeaching, paper-based approaches supported with CD-ROMs and web-based training.

Finally, health security should be marketed as a critical requirement for socioeconomic and political security to compel politicians and policymakers to prioritise IDSR and IHR for domestic funding. Importantly, countries should raise the profiles of the units in the $\mathrm{MoH}$ responsible for IDSR at the national and subnational levels.

\author{
Author affiliations \\ ${ }^{1}$ World Health Organization, Regional Office for Africa, Health Emergencies \\ programme, Brazzaville, Congo \\ ${ }^{2}$ Global Public Health Solutions, Atlanta, Georgia, USA \\ ${ }^{3}$ World Health Organization, Country Office, Kampala, Uganda \\ ${ }^{4}$ World Health Organization, Country Office, Juba, South Sudan \\ ${ }^{5}$ World Health Organization, Country Office, Free Town, Sierra Leone \\ ${ }^{6}$ World Health Organization, Country Office, Abuja, Nigeria \\ ${ }^{7}$ World Health Organization, Regional Office for Africa, Country Support, Brazzaville, \\ Congo
}

\begin{abstract}
Acknowledgements The authors thank the disease prevention and control authorities, the national surveillance staff at all levels of the health system, the WHO county office disease prevention and control officers and the IDSR focal person, and all persons who contributed to the documentation of this paper. The authors thank Olga Henao (US CDC), Andrea Long-Waganer (USAID), Christopher Murrill (US CDC), Michelle Sloan (UD CDC), Alden Bernard Aton (WHO) and Hellen Perry (independent consultant) for their review and helpful comments on the draft manuscript. Special thanks to WHO country and regional office executive management for their vision to adopt IDSR 20 years ago.
\end{abstract}

Contributors ISF, SCR, AAY, ZY, PN, MN, ON, JW, CN, CLO, WA, FCK and AOT planned, coordinated, conducted and supervised the IDSR rapid assessment and monitoring and evaluation of IDSR using the KPIs. All authors contributed to the manuscript, and read and approved the final manuscript.

Funding We acknowledge ongoing financial support for IDSR implementation from the US CDC and through a cooperation grant from the US Agency for International Development, Bureau for Africa (USAID/AFR), Washington, DC.

Competing interests None declared.

\section{Patient consent for publication Not required.}

Provenance and peer review Not commissioned; externally peer reviewed.

Data availability statement № additional data are available.

Open access This is an open access article distributed in accordance with the Creative Commons Attribution Non Commercial (CC BY-NC 4.0) license, which permits others to distribute, remix, adapt, build upon this work non-commercially, and license their derivative works on different terms, provided the original work is properly cited, appropriate credit is given, any changes made indicated, and the use is non-commercial. See: http://creativecommons.org/licenses/by-nc/4.0/.

\section{REFERENCES}

1. World Health Orgznisation. Health Emergencies Programme in the African Region: Annual ReportRegional Office for Africa; 2016. http:// www.afro.who.int/fr/node/8317

2. World Health Organisation, Regional Office for Africa. Mapping risks and the distribution of epidemics in the WHO African region, 2016; a technical report; 2016.

3. Heymann DL, Chen L, Takemi K, et al. Global health security: the wider lessons from the West African Ebola virus disease epidemic. The Lancet 2015;385:1884-901.

4. Grobbelaar AA, Weyer J, Moolla N, et al. Resurgence of yellow fever in Angola, 2015-2016. Emerg Infect Dis 2016;22:1854-5.

5. Lucey DR, Gostin LO. The emerging Zika pandemic: enhancing preparedness. JAMA 2016;315:865-6.

6. Rohr JR, Dobson AP, Johnson PTJ, et al. Frontiers in climate change-disease research. Trends Ecol Evol 2011;26:270-7.
7. Sutherst RW. Global change and human vulnerability to vector-borne diseases. Clin Microbiol Rev 2004;17:136-73.

8. Peyre M, Chevalier V, Abdo-Salem S, et al. A systematic scoping study of the socio-economic impact of Rift Valley fever: research gaps and needs. Zoonoses Public Health 2015;62:309-25.

9. Parham PE, Waldock J, Christophides GK, et al. Climate, environmental and socio-economic change: weighing up the balance in vector-borne disease transmission. Philos Trans $R$ Soc Lond $B$ Biol Sci 2015;370:20130551.

10. World Health organization (WHO). Ebola situation report-30 March 2016. Available: http://apps.who.int/ebola/current-situation/ebolasituation-report-30-march-2016 [Accessed 17 Jan 2019].

11. United Nations Development Group (UNDG). Socio-economic impact of Ebola virus disease in West African countries. A call for national and regional containment, recovery and prevention. Available: http://www.africa.undp.org/content/dam/rba/docs/ Reports/ebola-west-africa.pdf [Accessed 17 Jan 2019].

12. The World Bank. Ebola: most African countries avoid major economic loss but impact on guinea, Liberia, Sierra Leone remains crippling. Available: http://www.worldbank.org/en/news/pressrelease/2015/01/20/ebola-most-african-countries-avoid-majoreconomic-loss-but-impact-on-guinea-liberia-sierra-leone-remainscrippling [Accessed 17 Jan 2019].

13. The World Bank. The economic impact of the 2014 Ebola epidemic: short and medium term estimates for West Africa, 2014. Available: http://www.worldbank.org/en/region/afr/publication/the-economicimpact-of-the-2014-ebola-epidemic-short-and-medium-termestimates-for-west-africa [Accessed 17 Jan 2019].

14. The World Bank. Summary on the Ebola recovery plan: Sierra Leone. Available: http://www.worldbank.org/en/topic/ebola/brief/summaryon-the-ebola-recovery-plan-sierra-leone [Accessed 14 Jan 2019].

15. The World Bank. Summary on the Ebola recovery plan: guinea, 2015 Available: http://www.worldbank.org/en/topic/ebola/brief/summaryon-the-ebola-recovery-plan-guinea [Accessed 14 Jan 2019].

16. The World Bank. Summary on the Ebola recovery plan: Liberia economic stabilization and recovery plan (ESRP), 2015. Available: http://www.worldbank.org/en/topic/ebola/brief/summary-on-theebola-recovery-plan-liberia-economic-stabilization-and-recoveryplan-esrp [Accessed 14 Jan 2019].

17. Ottersen T, Hoffman SJ, Groux G. Ebola again shows the international health regulations are broken: what can be done differently to prepare for the next epidemic? Am J Law Med 2016;42:356-92.

18. Kluge $\mathrm{H}$, Martín-Moreno JM, Emiroglu N, et al. Strengthening global health security by embedding the international health regulations requirements into National health systems. BMJ Glob Health 2018;3(Suppl 1):e000656.

19. World Health Organisation. Integrated epidemiological surveillance of diseases: regional strategy for communicable diseases (resolution AFR/RC48/R2). Harare, Zimbabwe Forty-eighth Session of the WHO Regional Committee for Africa; 1998.

20. Kasolo F, Yoti Z, Bakyaita N, et al. IDSR as a platform for implementing IHR in African countries. Biosecur Bioterror 2013;11:163-9.

21. Lukwago L, Nanyunja M, Ndayimirije N, et al. The implementation of integrated disease surveillance and response in Uganda: a review of progress and challenges between 2001 and 2007. Health Policy Plan 2013;28:30-40.

22. World Health organization and Centers for Disease Control and Prevention. Technical guidelines for integrated disease surveillance and response in the African region, Brazzaville, Republic of Congo and Atlanta, USA: I-398; 2010.

23. World Health Organisation. International health regulations. Third Edition, 2005.

24. World Health Orhanisation. IHR emergency Committee concerning influenza pandemic (H1N1), 2009. Available: https://www.who.int/ihr/ procedures/pheic/en/= [Accessed 18 Jan 2019].

25. World Health Orhanisation. IHR emergency Committee concerning wild polio virus, 2014. Available: https://www.who.int/ihr/procedures/ pheic/en/= [Accessed 18 Jan 2019].

26. World Health Orhanisation. IHR emergency Committee concerning the West Africa Ebola outbreak, 2014. Available: https://www.who. int/ihr/procedures/pheic/en [Accessed 18 Jan 2019].

27. World Health Orhanisation. IHR emergency Committee concerning the Zika virus, 2016. Available: https://www.who.int/ihr/procedures/ pheic/en [Accessed 18 Jan 2019].

28. World Health Organization. Implementation of the international health regulations (2005): report of the review Committee on second extensions for establishing national public health capacities and on IHR implementation. Geneva WHO; 2015. http://apps.who.int/iris/ bitstream/10665/251717/1/B136_22Add1-en.pdf 
29. World Health Organisation. Report of the interim assessment panel on Ebola, 2015. Available: https://www.who.int/csr/resources/ publications/ebola/report-by-panel.pdf?ua=1 [Accessed 18 Jan 2019].

30. World Health Organisation. 66 regional Committee for Africa. resolution: regional strategy for health security and emergencies 2016-2020, document AF, 2016. Available: http://www.who.int/iris/ handle/10665/252834 [Accessed 18 Jan 2019].

31. World Health Organisation. The transformation agenda of the World Health organization Secretariat in the African region 2015 - 2020. Available: https://www.afro.who.int/regional-director/transformationagenda [Accessed 18 Jan 2019].

32. Nsubuga P, Brown WG, Groseclose SL, et al. Implementing integrated disease surveillance and response: four African countries experience, 1998-2005. Glob Public Health 2010;5:364-80.

33. Kihembo C, Masiira B, Nakiire L, et al. The design and implementation of the re-vitalised integrated disease surveillance and response (IDSR) in Uganda, 2013-2016. BMC Public Health 2018;18.

34. Mandyata CB, Olowski LK, Mutale W. Challenges of implementing the integrated disease surveillance and response strategy in Zambia: a health worker perspective. BMC Public Health 2017;17.
35. Adokiya MN, Awoonor-Williams JK, Barau IY, et al. Evaluation of the integrated disease surveillance and response system for infectious diseases control in northern Ghana. BMC Public Health 2015;15.

36. World Health Organisatio. Building health security Beyong Ebola. Report of the high level meeting, 2015. Available: http://apps.who. int/iris/bitstream/handle/10665/250133/WHO-HSE-GCR-2016.13eng.pdf [Accessed 18 Jan 2019].

37. Gostin LO. Global health security after Ebola: four global commissions. Milbank Q 2016;94:34-8.

38. Thierry N, Adeline K, Anita A, et al. A national electronic system for disease surveillance in Rwanda (elDSR): lessons learned from a successful implementation. Online J Public Health Inform 2014;6:e118.

39. Randriamiarana R, Raminosoa G, Vonjitsara N, et al. Evaluation of the reinforced integrated disease surveillance and response strategy using short message service data transmission in two southern regions of Madagascar, 2014-15. BMC Health Serv Res 2018;18.

40. Shoemaker TR, Balinandi S, Tumusiime A, et al. Impact of enhanced viral haemorrhagic fever surveillance on outbreak detection and response in Uganda. Lancet Infect Dis 2018;18:373-5. 